\title{
Vascular Calcifications, Arterial Aging and Arterial Remodeling in ESRD
}

\author{
Gérard M. London Bruno Pannier Sylvain J. Marchais \\ Service d'Hémodialyse, Hôpital F.H. Manhès, Fleury-Mérogis, France
}

\section{Key Words}

End-stage renal disease - Arterial stiffness • Arterial remodeling $\cdot$ Aging $\cdot$ Arterial calcifications

\begin{abstract}
Background: Accelerated arterial aging and inadequate outward arterial remodeling are observed in end-stage renal disease (ESRD) patients. Whether these changes could be closely associated with arterial calcifications has never been investigated. Methods: 155 ESRD patients and 105 age-, sex-, and blood pressure-matched control subjects were included. Common carotid artery (CCA) pressure, diameter, intimamedia thickness, elastic modulus, and presence of calcified plaques were measured ultrasonographically. Carotid artery stiffness was determined from simultaneously recorded CCA diameter and stroke changes in diameter and CCA pressure waveforms, obtained by applanation tonometry. Results: Compared with control subjects, ESRD patients had increased CCA systolic and pulse pressures $(p<0.001)$, larger CCA diameter $(p<0.001)$ and CCA intima-media thickness $(p<0.01)$ and similar CCA relative wall thickness. In ESRD patients the arterial remodeling was associated with increased CCA elastic modulus/stiffness ( $p<0.001)$. In ESRD patients the association between CCA elastic modulus and age was characterized by a steeper slope $(p=0.03)$, but after separation of uremic patients according to the presence of calcifications, the accelerated aging was observed only in calcified subjects. Despite higher CCA systolic and pulse pressures,
\end{abstract}

the CCA relative wall thickness was similar to controls indicating an inadequate pressure-associated remodeling. Moreover, the positive systolic pressure/relative thickness correlation observed in control subjects was lost with paradoxical negative correlation in calcified ESRD patients ( $p=$ 0.03). Conclusion: These results indicate that, in ESRD patients, accelerated arterial aging and inadequate arterial hypertrophy are closely associated with the calcifications of arterial walls. Inadequate hypertrophy is responsible for high circumferential stress applied on the vessels.

Copyright $\odot 2013$ S. Karger AG, Basel

\section{Introduction}

Arterial pathology is a leading cause of mortality in end-stage renal diseases (ESRD) $[1,2]$. Epidemiological studies in almost all populations have clearly shown that aging is the most determinant risk factor for cardiovascular diseases. This age-associated risk for the development of cardiovascular complications is associated with numerous deleterious changes in the structure of the arterial system. Among the most characteristic changes associated with aging are stiffening, i.e. arteriosclerosis (arterial hardening) and remodeling characterized by dilation, hypertrophy and increased length (tortuousness) of large arteries [3, 4]. The degeneration of elastic fibers is associated with an increase in collagen fibers and ground substance, and depositions of calcium [5]. In ESRD pa-

\section{KARGER \\ Fax +4161306 1234 \\ E-Mail karger@karger.ch}

www.karger.com
(C) $2013 \mathrm{~S}$. Karger AG, Basel

$0253-5068 / 13 / 0353-0016 \$ 38.00 / 0$

Accessible online at:

www.karger.com/bpu
Dr. Gérard M. London

Hôpital F.H. Manhès

8 , rue Roger Clavier

FR-91712 Fleury-Mérogis Cedex (France)

E-Mail glondon@club-internet.fr 
tients the arterial structural and functional changes are characterized by an accelerated influence of aging ('arterial progeria') $[6,7]$. Premature vascular aging and arterial stiffening are observed with progression of chronic kidney disease (CKD) and in ESRD. This accelerated aging is associated with outward remodeling of large vessels, characterized by an increased arterial radius not totally compensated for by artery wall hypertrophy [6-9]. Deposition of calcium salts in the walls of human arteries is a 'physiologically' inevitable consequence of aging, but the extent of calcifications is more pronounced in ESRD [10-12]. Arterial stiffening in CKD and ESRD patients is of multifactorial origin with arterial calcifications representing an important covariate, but the specific role of calcifications in the acceleration of the aging process and arterial remodeling in ESRD is not clear. In this study we analyze the role of calcifications in age-related functional and structural changes in a stable hemodialysis population.

\section{Methods}

\section{Subjects}

We studied 155 stable non-diabetic ESRD patients on hemodialysis, and 105 control subjects matched for age (53.7 \pm 15.3 vs. $53.6 \pm 13.9$ years), mean blood pressure (104.9 \pm 17.6 vs. 103.8 $\pm 15.1 \mathrm{~mm} \mathrm{Hg})$ and sex ratio $(1.40 \pm 0.49$ vs. $1.35 \pm 0.47)$. ESRD patients were enrolled if: (a) they had been on hemodialysis for at least 3 months; (b) they agreed to participate in the study, which was approved by our institutional review board, and (c) they were free of any CV complication during the 6 months preceding entry into the study. In ESRD patients all hemodynamic investigations were performed before the midweek dialysis. The study was approved by our institutional review board and all patients gave written informed consent.

\section{Blood Pressure Measurement}

Brachial blood pressure (BP) was measured with a mercury sphygmomanometer after $15 \mathrm{~min}$ of recumbency. The phase I and $\mathrm{V}$ of Korotkoff sounds were taken respectively as the systolic BP, and diastolic BP. The mean BP was determined by integration of the radial artery pressure wave contour recorded by applanation tonometry. Common carotid artery (CCA) pressure was recorded non-invasively by applanation tonometry with a pencil-type probe incorporating a high-fidelity Millar strain gauge transducer (SPT-301; Millar Instruments, Houston, Tex., USA). A detailed description of this system has been published previously [7, 13, 14]. The CCA pressure wave was calibrated assuming that brachial and carotid diastolic and mean BPs were equal. Mean BP on the CCA pressure wave was computed from the area of the CCA pressure wave in the corresponding heart period, and set equal to brachial mean BP. CCA pressure amplitude was then computed from diastolic BP and the position of mean BP on the CCA pressure wave.

Vascular Calcifications, Arterial Aging and Arterial Remodeling in ESRD
Common Carotid Artery Diameter and Intima-Media

Thickness

CCA diameter and wall motion were measured by a high-resolution B-mode echotracking system (wall-track system) allowing assessment of arterial wall displacement during the cardiac cycle. Measurements were done on the right CCA, $2 \mathrm{~cm}$ beneath the bifurcation. CCA lumen cross-sectional area (LCSA) was calculated as LCSA $=\pi(\text { CCA diameter })^{2} / 4$. CCA intima-media thickness (IMT) was measured on the far wall at the same level as the diameter measurements with computer-assisted acquisition and processing. The intima-media cross-sectional area (IMCSA) was calculated as IMCSA $=\pi(\text { CCA diameter } / 2+\mathrm{IMT})^{2}-\pi($ CCA diameter $/ 2)^{2}$ and wall/lumen ratio as 2IMT/CCA diameter (relative wall thickness). A complete detailed description of this system has been published previously [7, 13-15]. A localized echostructure encroaching into the vessel lumen was considered to be a plaque if the CCA IMT was $>50 \%$ thicker than neighboring sites [16]. Calcified plaque was determined from the presence of shadow cone projection (fig. 1). Measurements of CCA diameter and CCA IMT were always performed in plaque-free arterial segments.

CCA distensibility and elastic modulus $\left(\mathrm{E}_{\text {inc }}\right)$ were determined from changes in CCA diameter during the systole $\left(D_{s}\right.$ : systolic diameter; $\mathrm{D}_{\mathrm{d}}$ : diastolic diameter) and simultaneously measured CCA pulse pressure $(\Delta \mathrm{P})$ according to the following formulas: CCA distensibility $=2\left[\left(\mathrm{D}_{\mathrm{s}}-\mathrm{D}_{\mathrm{d}}\right) / \mathrm{D}_{\mathrm{d}}\right] / \Delta \mathrm{P}\left(\mathrm{kPa}^{-1} \cdot 10^{-3}\right)$. While distensibility provides information about 'elasticity' of the artery as a hollow structure, the incremental modulus of elasticity $\left(\mathrm{E}_{\text {inc }}\right)$ provides information on the properties of the wall material, independent of the geometry. $\mathrm{E}_{\text {inc }}$ was calculated $=3(1+$ LCSA $/$ IMCSA) $\cdot 1 /$ CCA distensibility.

\section{Statistical Analysis}

Data are expressed as mean $\pm \mathrm{SD}$. Continuous variables were compared using Student's t test. Sex (0, male; 1 , female), group $(0$, controls; 1 , ESRD) were used as dummy variables. Stepwise regression was used to analyze associations between hemodynamic parameters. Each predictor with a probability level of $\mathrm{p}<0.15$ identified by this analysis was subsequently tested in a multivariable linear correlation. To analyze the influence of calcifications on age- or pressure-related changes of arterial remodeling and mechanical properties, ESRD patients were separated into two groups: those with CCA plaque calcifications as ESRD Ca+, and those free of calcified plaques as ESRD Ca-. Differences were considered significant at $\mathrm{p}<0.05$. All tests were performed using NCSS 2000 software (J. Hintze, Kaysville, Utah, USA).

\section{Results}

Characteristics of the control population and ESRD patients are presented in table 1 . The two groups were similar with regard to the age-to-sex ratio. ESRD patients had a lower body surface area $(\mathrm{p}<0.01)$. ESRD patients had a similar mean and diastolic BP but higher carotid artery and brachial artery systolic and pulse pressures. CCA diameter and lumen area were increased in ESRD 

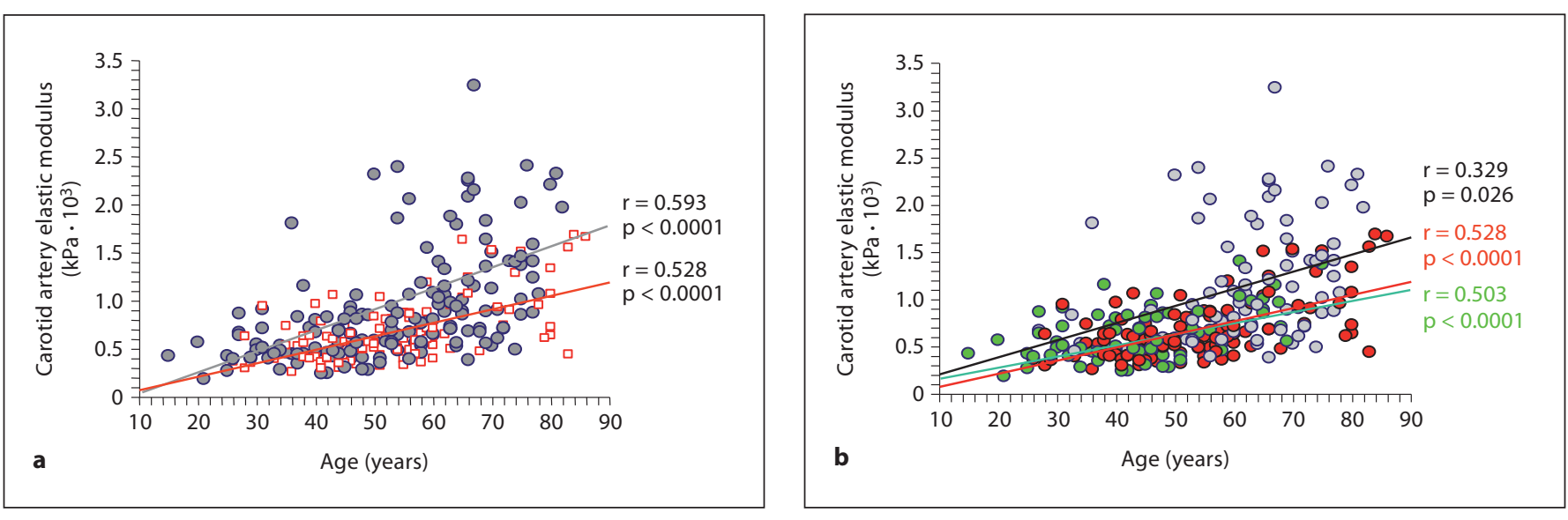

Fig. 1. a Correlations between common artery diameter elastic modulus and age in ESRD patients (gray circles) and controls (red squares). b Between control subjects (red circles) and ESRD patients according to the presence (gray circles) or absence of carotid calcifications (green circles).

$(\mathrm{p}<0.001)$ (table 1). The CCA IMT and intima-media cross-sectional area were increased in ESRD patients $(\mathrm{p}<0.001)$. The CCA wall-to-lumen ratio was similar in both groups. Systolic expansion in CCA diameter was similar in both groups, despite higher distending pressure in ESRD patients, and CCA stiffness was increased as characterized by reduced distensibility $(\mathrm{p}<0.01)$ and increased $\mathrm{E}_{\text {inc }}(\mathrm{p}<0.001)$.

The correlation between age and $\mathrm{E}_{\text {inc }}$ in the control population and ESRD patients is shown in figure 1 and characterized by a significantly steeper slope ( $\beta$ coefficient) of the correlation in ESRD ( $\mathrm{p}=0.048)$. As shown in figure $1 \mathrm{~b}$, this accelerated aging concerns the ESRD Ca+ population but not ESRD Ca- patients. The characteristics of these two groups are shown in table 2. Calcified patients are older, have higher CCA systolic and PP pressures, a larger CCA diameter and IMT, an increased $\mathrm{E}_{\text {inc, }}$, but a similar CCA relative wall thickness. In control subjects the CCA relative wall thickness is positively associated with an increased systolic pressure (fig. 2a) as characteristic for concentric remodeling. This correlation is not observed in non-calcified ESRD patients (fig. 2b) and is negative in patients with CCA calcifications (fig. 2c) indicating an inadequate hypertrophy remodeling.

\section{Discussion}

Confirming previous studies, the present study shows that ESRD disease is characterized by an accelerated ageassociated arterial stiffening and outward remodeling of
CCAs. The CCA elastic modulus and CCA diameter are increased in ESRD patients. CCA IMT is also increased but not enough to compensate for diameter enlargement, resulting in a chronic increase in arterial wall circumferential stress. The novelty of these arterial changes is observed principally in association with arterial calcifications.

Premature vascular aging and arterial stiffening are observed with progression of CKD and in ESRD. In ESRD this was well documented by the steeper relationship between aortic pulse wave velocity and age [6]. As shown in the present study, a similar steeper age-related increase in CCA elastic modulus is observed in ESRD (fig. 1a). In ESRD patients, the accelerated age-associated stiffening of CCA is observed only in the presence of CCA calcifications (fig. 1b), while in patients free of visible calcified plaques the relationship age and CCA elastic modulus is identical to that in control subjects (fig. 1b). Arterial stiffening in CKD and ESRD patients is of multifactorial origin with extensive arterial calcifications representing a major covariate $[6,17,18]$. Arterial calcification is a regulated process implicating osteogenic dedifferentiation of vascular smooth muscle into osteoblast-like cells under factors inducing and those opposing it, with plasma constituents maintaining minerals in solution and inhibiting their deposition in tissues [19-21]. Senescence of vascular smooth muscle cells enhances the calcification through initiating the osteoblastic transition [22]. As expected, the calcified ESRD patients were older but had lower serum albumin and higher C-reactive protein (table 2) in agreement with the role of inflamma- 
Table 1. Characteristics of the control group and ESRD patients (mean $\pm \mathrm{SD}$ )

\begin{tabular}{|c|c|c|c|}
\hline & Controls $(n=105)$ & $\operatorname{ESRD}(\mathrm{n}=155)$ & $\mathrm{p}$ value \\
\hline Age, years & $53.6 \pm 13.9$ & $53.7 \pm 15.3$ & NS \\
\hline Gender, ratio & $1.33 \pm 0.47$ & $1.41 \pm 0.49$ & NS \\
\hline Body surface area, $\mathrm{m}^{2}$ & $1.88 \pm 0.23$ & $1.71 \pm 0.21$ & $<0.0001$ \\
\hline Brachial systolic BP, mm Hg & $142.7 \pm 22$ & $151.2 \pm 29.4$ & $<0.01$ \\
\hline Brachial diastolic $\mathrm{BP}, \mathrm{mm} \mathrm{Hg}$ & $84 \pm 14.4$ & $81.8 \pm 15.2$ & NS \\
\hline Mean BP, mm Hg & $103.6 \pm 15.1$ & $104.9 \pm 17.6$ & NS \\
\hline CCA systolic BP, mm Hg & $134.4 \pm 20.8$ & $144.2 \pm 28.8$ & $<0.01$ \\
\hline CCA pulse pressure, $\mathrm{mm} \mathrm{Hg}$ & $50.3 \pm 16.8$ & $62.4 \pm 24.7$ & $<0.0001$ \\
\hline CCA diameter, $\mathrm{mm}$ & $7.25 \pm 0.97$ & $7.92 \pm 0.12$ & $<0.0001$ \\
\hline CCA lumen cross-sectional area, $\mathrm{mm}^{2}$ & $42.2 \pm 11.3$ & $50 \pm 14.2$ & $<0.0001$ \\
\hline CCA wall thickness, mm & $0.71 \pm 0.12$ & $0.77 \pm 0.12$ & $<0.001$ \\
\hline CCA wall cross-sectional area, $\mathrm{mm}^{2}$ & $18.2 \pm 5.1$ & $21.2 \pm 5.7$ & $<0.001$ \\
\hline CCA wall/lumen, ratio & $0.20 \pm 0.025$ & $0.195 \pm 0.024$ & NS \\
\hline CCA circumferential stress, $\mathrm{kPa}$ & $91.5 \pm 15.2$ & $100.2 \pm 24.5$ & $<0.001$ \\
\hline Systolic $\Delta$ CCA diameter, mm & $390 \pm 147$ & $415 \pm 160$ & NS \\
\hline $\mathrm{CCA} \mathrm{E}_{\text {inc }}, \mathrm{kPa} \cdot 10^{3}$ & $0.71 \pm 0.42$ & $0.90 \pm 0.55$ & $<0.001$ \\
\hline Left ventricular end-diastolic diameter, $\mathrm{mm}$ & $51.6 \pm 4.7$ & $52.8 \pm 6.3$ & NS \\
\hline Left ventricular posterior wall thickness, $\mathrm{mm}$ & $9.5 \pm 2.1$ & $10.6 \pm 2.0$ & $<0.001$ \\
\hline Interventricular wall thickness, $\mathrm{mm}$ & $9.6 \pm 2.2$ & $11 \pm 2.2$ & $<0.0001$ \\
\hline Left ventricular relative wall thickness & $0.37 \pm 0.07$ & $0.40 \pm 0.08$ & $<0.01$ \\
\hline
\end{tabular}

Table 2. Characteristics of ESTD patients according to the presence/absence of CCA calcifications (mean \pm $\mathrm{SD})$

\begin{tabular}{|c|c|c|c|}
\hline & $\begin{array}{l}\text { ESRD CCA } \\
\text { calcified }(\mathrm{n}=80)\end{array}$ & $\begin{array}{l}\text { ESRD CCA } \\
\text { non-calcified }(\mathrm{n}=75)\end{array}$ & $\mathrm{p}$ value \\
\hline Age, years & $62.4 \pm 11.5$ & $44.4 \pm 13.2$ & $<0.0001$ \\
\hline Gender, ratio & $1.38 \pm 0.48$ & $1.44 \pm 0.49$ & NS \\
\hline Body surface area, $\mathrm{m}^{2}$ & $1.72 \pm 0.20$ & $1.70 \pm 0.20$ & NS \\
\hline Brachial systolic BP, mm Hg & $157.4 \pm 30.4$ & $144 \pm 26.7$ & $<0.01$ \\
\hline Brachial diastolic $\mathrm{BP}, \mathrm{mm} \mathrm{Hg}$ & $78.3 \pm 14.6$ & $85.9 \pm 15.1$ & $<0.01$ \\
\hline Mean BP, $\mathrm{mm} \mathrm{Hg}$ & $104.7 \pm 17.8$ & $105.4 \pm 17.8$ & NS \\
\hline CCA systolic BP, mm Hg & $151.8 \pm 29.8$ & $135.9 \pm 25$ & $<0.001$ \\
\hline CCA pulse pressure, $\mathrm{mm} \mathrm{Hg}$ & $73.5 \pm 25.4$ & $49.7 \pm 16.7$ & $<0.001$ \\
\hline CCA diameter, $\mathrm{mm}$ & $8.38 \pm 1.07$ & $7.39 \pm 0.90$ & $<0.00001$ \\
\hline CCA wall thickness, $\mathrm{mm}$ & $0.827 \pm 0.10$ & $0.703 \pm 0.10$ & $<0.00001$ \\
\hline CCA wall/lumen, ratio & $0.20 \pm 0.25$ & $0.191 \pm 0.03$ & NS \\
\hline $\mathrm{CCA} \mathrm{E}_{\mathrm{inc}}, \mathrm{kPa} \cdot 10^{3}$ & $1.16 \pm 0.63$ & $0.63 \pm 0.26$ & $<0.00001$ \\
\hline CCA circumferential stress, $\mathrm{kPa}$ & $103.7 \pm 27$ & $96.3 \pm 20.8$ & 0.027 \\
\hline Serum albumin, $g / 1$ & $38.9 \pm 3$ & $40.5 \pm 3.2$ & $<0.01$ \\
\hline Highly sensitive C-reactive protein, $\mathrm{mg} / \mathrm{l}$ & $12.2 \pm 10.2$ & $5.9 \pm 6.7$ & $<0.00001$ \\
\hline Serum calcium, $\mathrm{mmol} / \mathrm{l}$ & $2.33 \pm 0.11$ & $2.31 \pm 0.11$ & NS \\
\hline Serum phosphates, mmol/l & $1.84 \pm 0.44$ & $1.76 \pm 0.39$ & NS \\
\hline Serum parathormone, $\mathrm{pg} / \mathrm{ml}$ & $260 \pm 223$ & $361 \pm 320$ & $<0.01$ \\
\hline Serum cholesterol, mmol/l & $5.15 \pm 0.23$ & $5.12 \pm 0.25$ & NS \\
\hline Dialysis vintage, months & $87 \pm 85$ & $65 \pm 63$ & NS \\
\hline
\end{tabular}




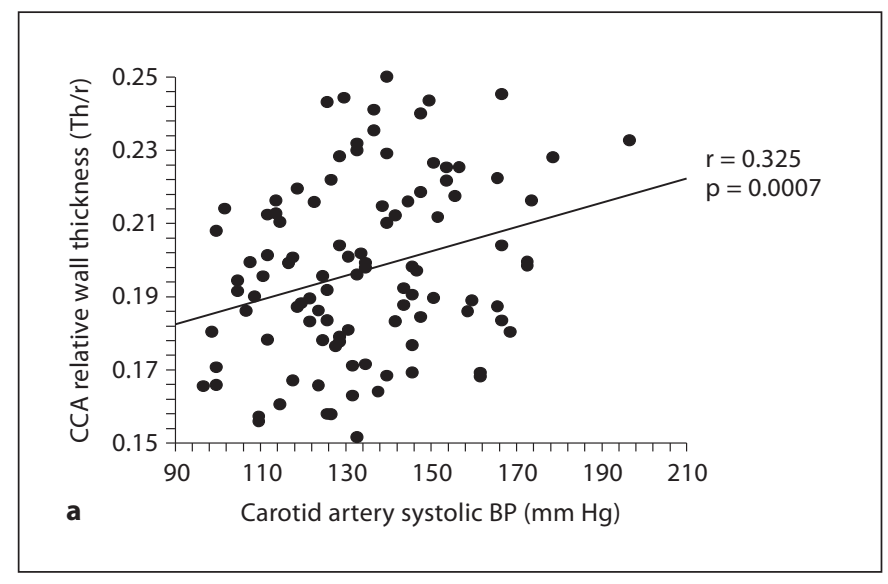

Fig. 2. Correlations between CCA systolic BP and CCA relative wall thickness (IMT/radius ratio) in controls (a) and ESRD patients according to the absence (b) and presence (c) of calcifications.

tion as a trigger for osteoblastic transdifferentiation [23]. Mineral and bone disorders are the most frequently observed factors associated with arterial remodeling and functional alterations in CKD and ESRD. ESRD patients with calcifications had a lower parathormone level as the only statistically different mineral disorder parameter.

Characteristics of arterial remodeling depend on the nature of hemodynamic stimuli. According to Laplace's law, arterial tensile stress $(\sigma)$ is proportional to transmural pressure $(P)$ and radius $(r)$, and inversely proportional to wall thickness $(h)(\sigma=P r / h)$. In response to increased $\mathrm{BP}$ or arterial radius, vessel wall thickening and a higher wall-to-lumen ratio [24, 25] maintain tensile stress. In contrast to observations made in non-uremic atherosclerosis patients, in CKD patients the wall thickening did not compensate for the increased lumen diameter, resulting in heightened circumferential wall stress $[8,9]$. Moreover, these recent studies showed that carotid IMT declined during worsening CKD $[8,9]$, and in ESRD patients the hypertrophic response is characteristically
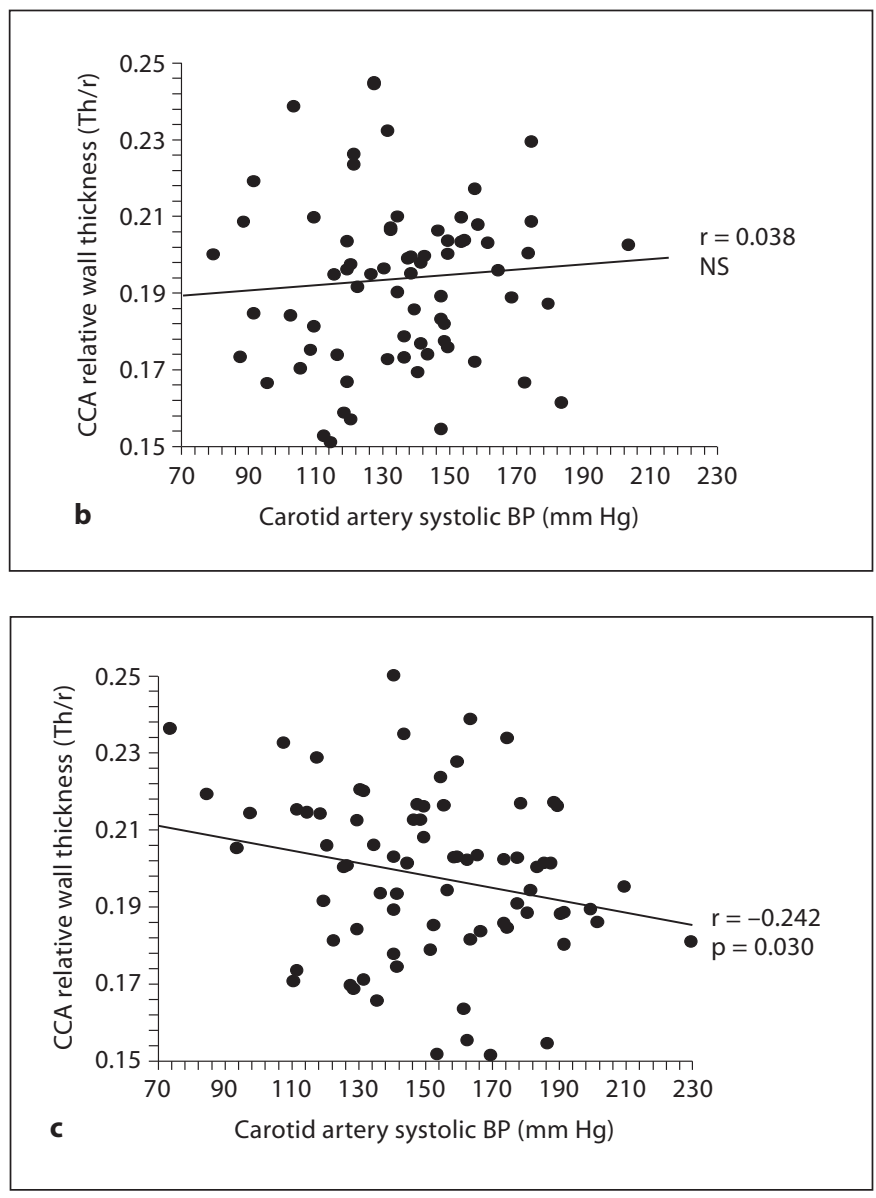

'inadequate' $[6,26]$. As shown in figure 2 , the positive relationship between systolic BP and arterial wall-to-lumen ratio observed in control subjects (fig. 2a) is lost in noncalcified ESRD patients (fig. 2b), and negative in patients with calcifications (fig. 2c). The high tensile stress and limited arterial capacity to hypertrophy is a pathological continuum observed in CKD and ESRD.

The mechanisms of the association between the presence of arterial calcification and inadequate hypertrophy are not evident. Excessive vascular smooth muscle cell apoptosis is one hypothesis which could link inadequate hypertrophic response to calcifications. Shroff et al. [27] found apoptosis-related rarefaction of vascular smooth muscle cells in children with ESRD compared to patients without CKD. As the calcifications were stratified according to the presence of 'visible plaque calcification', it does not eliminate the presence of increased calcium content in patients free of macroscopic calcium deposits and could account for an inadequate response in the 'non-calcified' ESRD group. Other 
mechanisms could be involved. Metalloproteinases play a role in outward vascular remodeling, and several studies have shown that serum-level variations of metalloproteinases and their inhibitors are increased in CKD patients [28-30].
In conclusion, these results indicate that, in ESRD patients, accelerated arterial aging and inadequate arterial hypertrophy are closely associated with the calcifications of arterial walls.

\section{References}

$>1$ Lindner A, Charra B, Sherrard D, Scribner BM: Accelerated atherosclerosis in prolonged maintenance hemodialysis. N Engl J Med 1974;290:697-702.

$\checkmark 2$ Blacher J, Pannier B, Guérin AP, et al: Carotid arterial stiffness as a predictor of cardiovascular and all-cause mortality in endstage renal disease. Hypertension 1998;32: 570-574.

$\checkmark 3$ Benetos A, Laurent S, Hoeks AP, et al: Arterial alterations with aging and high blood pressure: a noninvasive study of carotid and femoral arteries. Arterioscler Thromb Vasc Biol 1993;13:90-97.

4 O'Rourke MF: Arterial aging: pathophysiological principles. Vasc Med 2007;12:329341.

$\checkmark 5$ Virmani R, Avolio AP, Mergner WJ, et al: Effects of aging on aortic morphology in populations with high and low prevalence of hypertension and atherosclerosis. Am J Patho 1991;139:1119-1129.

-6 Pannier B, Guérin AP, Marchais SJ, et al: Arterial structure and function in end-stage renal disease. Artery Res 2007;1:79-88.

$>7$ London GM, Guérin AP, Marchais SJ, et al: Cardiac and arterial interactions in endstage renal disease. Kidney Int 1996;50:600608 .

$>8$ Briet M, Bozec E, Laurent S, et al: Arterial stiffness and enlargement in mild-to-moderate chronic kidney disease. Kidney Int 2006;69:350-357.

$>9$ Briet M, Collin C, Karras A, et al: Arterial remodeling associates with CKD progression. J Am Soc Nephrol 2011;22:967-974.

10 Braun J, Oldendorf M, Moshage W, et al: Electron beam computed tomography in the evaluation of cardiac calcifications in chronic dialysis patients. Am J Kidney Dis 1996;27: 394-401.
11 Goodman WG, Goldin J, Kuizon BD, et al: Coronary artery calcification in young adults with end-stage renal disease who are undergoing dialysis. N Engl J Med 2000;342: 1478-1483.

12 London GM, Guérin AP, Marchais SJ, et al: Arterial media calcification in end-stage renal disease: impact on all-cause and cardiovascular mortality. Nephrol Dial Transplant 2003;8:1731-1740.

13 Hoeks APG, Brands PJ, Smeets FA, Reneman RS: Assessment of distensibility of superficial arteries. Ultrasound Med Biol 1990;16: 121-128.

14 London GM, Pannier B, Guérin AP, et al: Cardiac hypertrophy, aortic compliance, peripheral resistance, and wave reflection in end-stage renal disease: comparative effects of ACE inhibition and calcium channel blockade. Circulation 1994;90:2786-2796.

15 London GM, Guérin AP, Pannier B, et al: Increased systolic pressure in chronic uremia: role of arterial wave reflections. Hypertension 1992;20:10-19.

16 Guérin AP, London GM, Marchais SJ, Métivier F: Arterial stiffening and vascular calcifications in end-stage renal disease. $\mathrm{Ne}$ phrol Dial Transplant 2000;15:1014-1021.

17 Raggi P, Bellasi A, Ferramosca E, et al: As sociation of pulse wave velocity with vascular and valvular calcification in hemodialysis patients. Kidney Int 2007;71:802-807.

18 Sigrist MK, Taal MW, et al: Progressive vascular calcification over 2 years is associated with arterial stiffening and increased mortality in patients with stages 4 and 5 chronic kidney disease. Clin J Am Soc Nephrol 2007; 2:1241-1248.

19 Schoppet M, Shroff RC, Hofbauer LC, Shanahan CM: Exploring the biology of vascular calcification in chronic kidney disease: what's circulating? Kidney Int 2008;73:384390.

20 Demer LL, Tintut Y: Vascular calcification: pathobiology of multifaceted disease. Circulation 2008;117:2938-2948.
21 Moe SM, Chen NX: Mechanisms of vascular calcification in chronic kidney disease. J Am Soc Nephrol 2008;19:213-216.

22 Nahkano-Kurimoto R, Ikeda K, Uraoka M, et al: Replicative senescence of vascular smooth muscle cells enhances the calcification through initiating the osteoblastic transition. Am J Physiol Heart Circ Physiol 2009; 297:H1673-H1684.

23 Shao J-S, Cheng S-L, Towler DA: Inflammation and the osteogenic regulation of vascular calcification. A review and prospective. Hypertension 2010;55:579-592.

24 Gibbons GH, Dzau VJ: The emerging concept of vascular remodeling. N Engl J Med 1994;330:1431-38.

25 Dzau VJ: The role of mechanical and humoral factors in growth regulation of vascular smooth muscle and cardiac myocytes. Curr Opin Nephrol Hypertens 1993;2:27-32.

26 Briet M, Boutouyrie P, Laurent S, London GM: Arterial stiffness and pulse pressure in CKD and ESRD. Kidney Int 2012;82:388400.

27 Shroff RC, McNair R, Figg N, et al: Dialysis accelerates medial vascular calcification in part by triggering smooth muscle cell apoptosis. Circulation 2008;118:1748-1757.

28 Ota R, Kurihara C, Tsou TL, et al: Roles of matrix metalloproteinases in flow-induced outward vascular remodeling. J Cereb Blood Flow Metab 2009;29:1547-1558.

29 Hörstrup JH, Gehrmann M, Schneider B, et al: Elevation of serum and urine levels of TIMP-1 and tenascin in patients with renal disease. Nephrol Dial Transplant 2002;17: 1005-1013.

30 Chung AW, Yang HH, Kim JM, et al: Upregulation of matrix metalloproteinase- 2 in the arterial vasculature contributes to stiffening and vasomotor dysfunction in patients with chronic kidney disease. Circulation 2009; 120:792-801.
Vascular Calcifications, Arterial Aging and Arterial Remodeling in ESRD 